\title{
Plasma advanced oxidative protein products are associated with anti-oxidative stress pathway genes and malaria in a longitudinal cohort
}

Guicheng Zhang ${ }^{1,6^{*}}$, Oleksii A Skorokhod², Siew-Kim Khoo', Ruth Aguilar ${ }^{3,4,5}$, Selma Wiertsema', Augusto J Nhabomba ${ }^{3}$, Tiziana Marrocco ${ }^{2}$, Michelle McNamara-Smith', Maria Nelia Manaca ${ }^{3}$, Arnoldo Barbosa ${ }^{3}$, Llorenç Quintó ${ }^{4,5}$, Catherine M Hayden' ${ }^{1}$, Jack Goldblatt ${ }^{1}$, Caterina Guinovart ${ }^{3,4,5}$, Pedro L Alonso ${ }^{3,4,5}$, Carlota Dobaño $0^{3,4,5}$, Evelin Schwarzer ${ }^{2 \dagger}$ and Peter N LeSouëf ${ }^{1 \dagger}$

\begin{abstract}
Background: Advanced oxidation protein products (AOPP) are newly identified efficient oxidative stress biomarkers. In a longitudinal birth cohort the effects were investigated of genetic polymorphisms in five oxidative pathway genes on AOPP levels.

Methods: This study is part of a three-arm randomized, double-blind, placebo-controlled trial. Three hundred and twelve children were included in the present study with AOPP levels measured at 2.5, 5.5, 10.5, 15 and 24 months of age. Twelve polymorphisms were genotyped in five oxidative stress pathway genes: glutathione reductase (GSR), glutamylcysteine synthetase (GCLC), glutathione S-transferase (GST) P1, haem oxygenase 1 (HMOX1) and superoxide dismutase 2 (SOD2) in 298 children. There were 284 children assessed for anaemia and clinical malaria infection at the age of 24 months.

Results: Two principal components (PCA1 and PCA2) were derived from the AOPP levels measured at the five time points. PCA1 was significantly associated with anaemia $(p=0.0002)$, and PCA2 with clinical malaria infection $(p=0.047)$. In the K-Means Cluster Analysis based on levels of AOPP, children were clustered into two groups: Group A (lower AOPP levels) and Group B (higher AOPP levels). The cluster membership was significantly associated with anaemia ( $p=0.003$ ) as well as with the GSR RS3594 polymorphism ( $p=0.037$ ). Mixed linear regression analyses found that the single nucleotide polymorphisms GCLC RS10948751 and HMOX1 RS17885925 were significantly associated with AOPP levels ( $p=0.030$ and $p=0.027$, respectively).
\end{abstract}

Conclusion: Plasma AOPP levels were predictive for anaemia and oxidative stress markers for clinical malaria infection in two year old children. Several polymorphisms in GCLC, GSR and HMOXI genes were associated with oxidative stress status of these children.

Keywords: Malaria, Anaemia, Oxidative stress, AOPP, Oxidative pathway genes

\footnotetext{
* Correspondence: guicheng.zhang@uwa.edu.au

${ }^{\dagger}$ Equal contributors

${ }^{1}$ School of Paediatrics and Child Health, University of Western Australia, c/o

100 Roberts Rd, Subiaco, WA 6008 Perth, Australia

${ }^{6}$ School of Public Health, Curtin University, Perth, Australia

Full list of author information is available at the end of the article
} 


\section{Background}

Oxidative stress is a common pathogenic mechanism underlying the development of many diseases and conditions including malaria infection, in which both the host and the parasite are under its effects. Adapting to the oxidative stress exerted by the host immune response against malaria infection, Plasmodium falciparum has developed an elaborate reduction-oxidation (redox) system to maintain adequate antioxidant defence throughout its complex life cycle [1]. In humans, oxidative changes resulting from malaria infection are central to the host protective response against the malaria parasite, and to some of the pathophysiology associated with clinical malaria infection. Enhanced oxidative stress reduces erythrocyte deformability [2,3], contributing to haemolysis, and the development of anaemia [4]. Although oxidative stress, anaemia and malaria infection are closely related in their pathogenic mechanisms, their complex relationships and the functional relevance of oxidative stress genes are poorly understood.

Oxidative pathway genes have been extensively investigated for associations with different phenotypes for their anti-oxidative effects on a range of conditions and diseases $[5,6]$. Genetic variants in glutathione S-transferase (GST) genes have been reported to be associated with susceptibility to many chronic inflammatory conditions and other diseases including malaria [7,8], anaemia [9], asthma [10], allergy [10], chronic obstructive pulmonary disease (COPD) [11], diabetes [12], cardiovascular diseases [12] and cancer [13]. Glutathione reductase (GSR) is also central to cellular antioxidant defence as it reduces oxidized glutathione disulphide (GSSG) to the sulfhydryl form GSH. Glutamate cysteine ligase, also known as gamma-glutamylcysteine synthetase, has a heavy catalytic subunit (GCLC) and is the rate limiting enzyme of glutathione synthesis that plays a crucial role in the intracellular antioxidant defence system. Haem oxygenase 1 (HMOX1), which degrades haem into biliverdin, carbon monoxide and free iron, is an essential enzyme in haem catabolism and protects against oxidative tissue damage. Superoxide dismutase 2 (SOD2) is also an important intracellular antioxidant enzyme. Numerous studies have reported on associations of the genetic variants in GSR [11], GCLC [14,15], HMOX1 [16] and SOD2 [17] with oxidative stress related disorders and conditions including malaria $[16,18,19]$.

Evidence of oxidative stress, or an antioxidant status, is usually assessed using biomarkers that reflect the actual oxidative stress in a tissue or the whole body. Plasma proteins, predominantly albumin and fibrinogen, undergo molecular modifications by oxidation which can be measured as advanced oxidation protein products (AOPP), which were first identified by Witko-Sarsat et al. as efficient oxidative stress biomarkers in uraemic patients $[20,21]$. Further studies confirmed AOPP concentrations as inflammatory markers in several diseases [22,23], but there is no report of any investigation on AOPP in malaria infection prior to this study.

In the AgeMal (Age of exposure and immunity to malaria in infants) collaborative study (ClinicalTrials.gov identifier NCT00231452), the genetic effects were investigated in young children of 12 functionally important polymorphisms in five oxidative pathway genes regarding their functional relevance for oxidative stress status measured as AOPP levels, as well as for the two phenotypes of anaemia and clinical malaria infection. Genetic variants in GCLC and $H M O X 1$ were associated with AOPP concentrations measured at five time points in the first two years of life. The AOPP biomarker was associated with anaemia and clinical malaria infection ascertained at two years of age. There is evidence that oxidative stress pathway genes contribute to the balance between a pro- and anti-oxidant status that is related to the development of anaemia and clinical malaria infection in young children.

\section{Methods \\ Study population}

This study is part of the AgeMal project consisting of a three-arm randomized, double-blind, placebo-controlled trial aimed at determining the importance of time of exposure to $P$. falciparum during the first year of life for the development of naturally acquired immunity [24]. The study was conducted in the Manhiça District, Maputo Province, in southern Mozambique, where transmission of $P$. falciparum is perennial with marked seasonality and moderate intensity, and the entomological inoculation rate of 38 infective bites/person/year [25]. The study population has been previously described [24,26,27]. Briefly, HIV-negative pregnant women were recruited during the third trimester of pregnancy and written informed consent was sought to enrol their newborn children in the study. The controlled exposure to $P$. falciparum infection was fulfilled with different protocols for administration of monthly chemoprophylaxis with sulphadoxine-pyrimethamine plus artesunate to the children during the first year of life in a three-arm intervention trial. A total of 312 infants were included in the study, with AOPP measured at 2.5, 5.5, 10.5, 15 and 24 months of age, and $>88 \%$ of children analysed at each of the five time points. There were 284 children who had their anaemia and clinical malaria infection status determined at the age of 24 months, and DNA samples were available from 298 children. The study was approved by the National Mozambican Ethics Committee, the Hospital Clínic of Barcelona Ethics Review Committee, the Bioethical Committee of the Torino University School of Medicine, and the Princess Margaret Hospital for Children Ethics Committee (1473/EP) in Perth. 


\section{Genotyping}

Genomic DNA was extracted from peripheral blood mononuclear cells by an automated DNA extraction instrument (Autopure LS; QIAGEN, Hilden, Germany). Genetic polymorphisms were selected from the five oxidative stress pathway genes: GSR, GCLC, GST P1, HMOX1 and $S O D 2$ based on their potential functional importance and estimated minor allele frequency $(>10 \%)$ in Africans. Two single nucleotide polymorphisms (SNPs) were genotyped in GSR, 3 in GCLC, 3 in GST P1, 2 SNPs and 1 AG deletion in $H M O X 1$, and $1 \mathrm{SNP}$ in SOD2. The genomic locations of these polymorphisms in the five genes are shown in Additional file 1. Genotyping of the 11 SNPs and 1 deletion was performed by the Australian Genome Research Facility using the iPLEX assay on the MassARRAY system (Sequenom, San Diego, CA) [28] according to the manufacturer's instructions.

\section{Measurement of AOPP concentration in plasma}

Spectrophotometric determination of AOPP plasma levels was performed by modification of the Witko-Sarsat's method in a micro-plate reader [20,29]. Briefly, $200 \mu \mathrm{l}$ of plasma diluted 1:10 in PBS and chloramine-T standard samples $(0-100 \mu \mathrm{mol} / \mathrm{l})$ were pipetted into a 96-well UVtransparent plate. Eight $\mu \mathrm{l}$ of $1.16 \mathrm{M}$ KI were added to each standard well, followed by $30 \mu \mathrm{l}$ of acetic acid added two minutes later. The absorbance read at $340 \mathrm{~nm}$ against a blank was referred to the standard absorbance. AOPP concentrations were expressed as $\mu \mathrm{mol} / \mathrm{l}$ of plasma.

\section{Definitions of anaemia and clinical malaria infection}

A clinical malaria episode was defined as axillary temperature $\geq 37.5^{\circ} \mathrm{C}$, or history of fever within the prior $24 \mathrm{~h}$, plus the presence in peripheral blood of $P$. falciparum asexual stage parasites of any density, determined by microscopy following standard quality control procedures [24]. Anaemia was defined as haemoglobin $(\mathrm{Hb})<8 \mathrm{~g} / \mathrm{dl}$ or packed cell volume $(\mathrm{PCV})<25 \%$ (if $\mathrm{Hb}$ results were not available), which corresponds to a moderate to severe degree of anaemia.

\section{Statistical analysis}

For the 12 polymorphisms in the five oxidative stress pathway genes, Hardy-Weinberg equilibrium was examined using the online tool [30]. The levels of AOPP at the five time points $(2.5,5.5,10.5,15$ and 24 months of age) were log transformed to have an approximately normal distribution. Principal component analysis (PCA), which can find a linear combination of variables and in which the combination variables accounts for as much variation in the original variables as possible, was employed to compute the component scores for AOPP levels at the five time points. K-Means Cluster Analysis was used to investigate the cluster membership of individual children based on levels of AOPP at the five time points. Children were clustered into two groups: Group A (lower AOPP levels) and Group B (higher AOPP levels).

The associations between genotypes and PCA scores of AOPP levels were investigated using analysis of variance and independent sample $t$ test, when appropriate. The associations of PCA scores of AOPP levels were also investigated with cluster membership, anaemia and clinical malaria infection at the age of 24 months using independent sample $t$ tests. Chi-square tests were employed to investigate the associations of genotypes, anaemia, and malaria infection with cluster membership. A mixed linear regression model was further employed to investigate the associations of genotypes with levels of AOPP adjusting for gender and presence/absence of anaemia. Other potential confounding factors were investigated for their association with levels of AOPP. Analyses were conducted using SPSS (PASW Statistics 18). All p-values are two-sided and were considered significant when $<0.05$.

\section{Results \\ Genotypes}

Eleven single nucleotide and 1 insertion/deletion polymorphisms were genotyped in five functionally important oxidative stress pathway genes in 298 young children. Table 1 shows the frequencies of the polymorphisms in these genes. The insertion/deletion variant of RS17883725 in HMOX1 was not in Hardy-Weinberg Equilibrium so it was excluded from further analyses. There was also complete linkage disequilibrium for the RS10948751 and RS7742367 SNPs in the GCLC gene, therefore, only RS10948751 was included in further analyses.

\section{Plasma AOPP}

Plasma AOPP levels were measured in 302 children at 2.5 months, 300 at 5.5 months, 296 at 10.5 months, 283 at 15 months and 274 at 24 months of age, showing decreasing levels by age (Table 2). 235 children had plasma AOPP measured at all five time points.

\section{Factor and cluster analysis on plasma AOPP levels}

Using PCA two components were derived that explained $50 \%$ of the variation of plasma AOPP levels at the five points. The levels of AOPP at the first four time points (2.5, 5.5, 10.5 and 15 months of age) significantly and positively contributed to the first component score (PCA1) that accounted for $30 \%$ of the variation of plasma AOPP levels at the five time points. The levels of AOPP at 24 months of age significantly and positively contributed to the second component score (PCA2) that accounted for $20 \%$ of the variation of the plasma AOPP levels at the five time points. In addition, the levels of AOPP at 2.5 and 5.5 months of age negatively contributed to the PCA2. Then, the PCA1 was related to plasma AOPP levels before 
Table 1 Frequencies of the 12 polymorphisms in the five oxidative pathway genes

\begin{tabular}{llllll}
\hline & Genotypes & $n$ & $\%$ & MAF & HWE \\
\hline GSR & & & & &
\end{tabular}

RS1002149(G/T)

$\begin{array}{lllll}\text { GG } & 159 & 55.0 & 24.6 & 0.11 \\ \text { GT } & 118 & 40.8 & & \\ \Pi & 12 & 4.2 & & \end{array}$

RS3594 (C/A)

$\begin{array}{lll}\text { CC } & 243 & 82.1 \\ \text { CA } & 50 & 16.9 \\ \text { AA } & 3 & 1.0\end{array}$

GCLC

RS10948751 (A/C)

$\begin{array}{lll}\text { AA } & 104 & 35.6 \\ \text { CA } & 139 & 47.6 \\ \text { CC } & 49 & 16.8\end{array}$

RS1901773 (G/C)

$\begin{array}{lll}\text { GG } & 69 & 25.6 \\ \text { CG } & 142 & 52.6 \\ \text { CC } & 59 & 21.9\end{array}$

RS7742367 (T/C)

$\begin{array}{lll}\Pi 1 & 100 & 35.7 \\ \mathrm{CT} & 132 & 47.1 \\ \mathrm{CC} & 48 & 17.1\end{array}$

\section{GSTP1}

RS1695 (A/G)

$\begin{array}{lll}\text { AA } & 81 & 28.0 \\ \text { AG } & 142 & 49.1 \\ \text { GG } & 66 & 22.8\end{array}$

RS17593068 (T/G)

$\begin{array}{lll}\text { Tा } & 79 & 28.0 \\ \text { TG } & 129 & 45.7 \\ \text { GG } & 74 & 26.2\end{array}$

RS6591256 (A/G)

$\begin{array}{lll}\text { AA } & 77 & 26.6 \\ \text { AG } & 146 & 50.3 \\ \text { GG } & 67 & 23.1\end{array}$

HMOX1

RS11555832 (T/C)

$\begin{array}{lll}\Pi 1 & 107 & 37.4 \\ \mathrm{CT} & 129 & 45.1 \\ \mathrm{CC} & 50 & 17.5\end{array}$

RS17883725 (AG/DEL)

AG
$81 \quad 29.2 \quad 49.5$

$9.5 \quad 0.73$

Table 1 Frequencies of the 12 polymorphisms in the five oxidative pathway genes (Continued)

$\begin{array}{lll}\text { AG.DEL } & 118 & 42.6 \\ \text { DEL.DEL } & 78 & 28.2\end{array}$

RS17885925 (T/C)

$\begin{array}{lllll}\pi & 275 & 92.3 & 3.9 & 1.0 \\ C T & 23 & 7.7 & & \end{array}$

SOD2

RS4880 (T/C)

$\begin{array}{lllll}\pi & 95 & 32.3 & 42.3 & 0.55 \\ \text { CT } & 149 & 50.7 & & \\ \text { CC } & 50 & 17.0 & & \end{array}$

MAF Minor Allele Frequency.

HWE Hardy-Weinberg Equilibrium.

15 months of age, and the PCA2 was positively correlated with plasma AOPP levels at 24 months of age and negatively correlated with plasma AOPP levels in infants less than 6 months of age. Additional file 1 shows the two component matrix with the plasma AOPP levels at the five time points.

Based on the levels of AOPP at the five time points, the children were clustered into two groups: Group A (lower AOPP levels) and Group B (higher AOPP levels). Group A included 161 children and Group B included 151 children. It was expected that the cluster membership would be associated with the levels of AOPP at the five time points as well as to the two PCA components, as the membership was defined from the levels of AOPP. Figure 1 shows the differences in the levels of AOPP (Figure 1A) and in the two principal components (Figure 1B) between children in Group A and Group B. Children in Group A had consistently and significantly lower levels of AOPP at the five time points, and lower scores of PCA1 $(\mathrm{p}<0.0001)$.

Anaemia and clinical malaria infection at $\mathbf{2 4}$ months of age Among the 284 children who were followed up to the age of 24 months, 23 (8.1\%) had anaemia and 32 (11.3\%) had clinical malaria infection at this last time point.

Table 2 Levels of AOPP by cross-section

\begin{tabular}{|c|c|c|c|c|}
\hline \multirow{2}{*}{$\begin{array}{l}\text { Months } \\
\text { of age }\end{array}$} & \multirow[t]{2}{*}{$\mathrm{n}$} & \multirow{2}{*}{$\begin{array}{c}\mathrm{GM} \\
(\mu \mathrm{mol} / \mathrm{L})\end{array}$} & \multicolumn{2}{|c|}{$95 \% \mathrm{Cl}$} \\
\hline & & & Lower & Upper \\
\hline 2.5 & 302 & 352.4 & 329.5 & 376.8 \\
\hline 5.5 & 300 & 263.9 & 245.4 & 283.9 \\
\hline 10.5 & 296 & 207.5 & 192.3 & 223.9 \\
\hline 15 & 283 & 154.0 & 141.6 & 167.5 \\
\hline 24 & 274 & 104.2 & 96.8 & 112.1 \\
\hline
\end{tabular}

GM Geometric mean.

Cl Confidence Interval. 


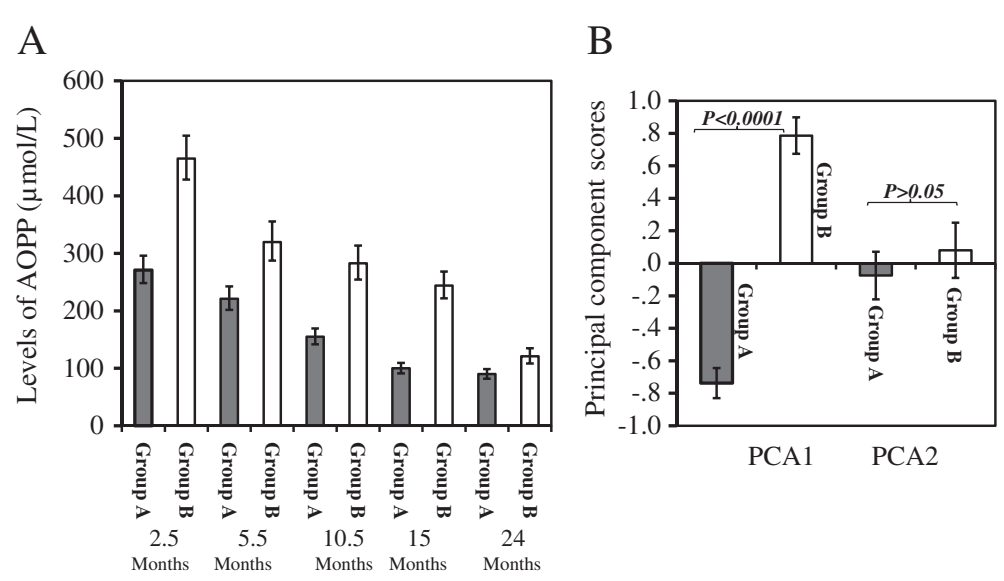

Figure 1 AOPP levels at the five time points and PCA scores stratified by cluster membership. A: AOPP levels (geometric mean and 95\% confidence intervals) at the five time points; B: PCA scores; Cluster membership was clarified using K-Means Cluster Analysis.

Generally, children with anaemia at 24 months had higher levels of plasma AOPP at all five time points, with significant differences at ages 2.5 months $(\mathrm{p}=0.014)$ and 15 months $(\mathrm{p}=0.001)$ (Figure 2A). Children with anaemia at 24 months had significantly higher PCA1 scores $(\mathrm{p}=0.0002)$, but not higher PCA2 (Figure 2B). Children with clinical malaria infection at age 24 months did not have significantly higher AOPP levels at ages 2.5, 5.5, 10.5 and 15 months, but had significantly higher AOPP levels at 24 months (Figure 3A). Clinical malaria infection at age 24 months did not associate with PCA1, but was significantly associated with an increased PCA2 $(\mathrm{p}=0.047)$ (Figure 3B).

The associations of the cluster membership were also investigated with anaemia and clinical malaria infection at age 24 months. Children in Group A, that had lower levels of AOPP, had a significantly lower prevalence of anaemia compared with those in Group B (3.4\% vs.
$13.0 \%, p=0.003)$. The odds ratio of $\mathrm{B}$ membership for anaemia was 4.23 (95\% confidence interval: 1.53 - 11.7). No association was found between cluster membership and clinical malaria infection at age 24 months.

\section{Associations of genotypes with the PCA scores, cluster membership and anaemia}

The associations of the different genotypes were investigated in the five oxidative pathway genes with the two PCA scores, with the cluster membership and with anaemia. No significant association was found with PCA1, however GCLC RS10948751 was significantly associated with PCA2 (Figure 4). No genotypes were associated with the cluster membership except for RS3594 in GSR (Figure 5A). The CC homozygotes had a significantly higher percentage of Group B compared with children with CA or AA genotypes (52.6\% vs. $36.5 \%, \mathrm{p}=0.037)$ (Figure 5A). The CC homozygotes also had a higher
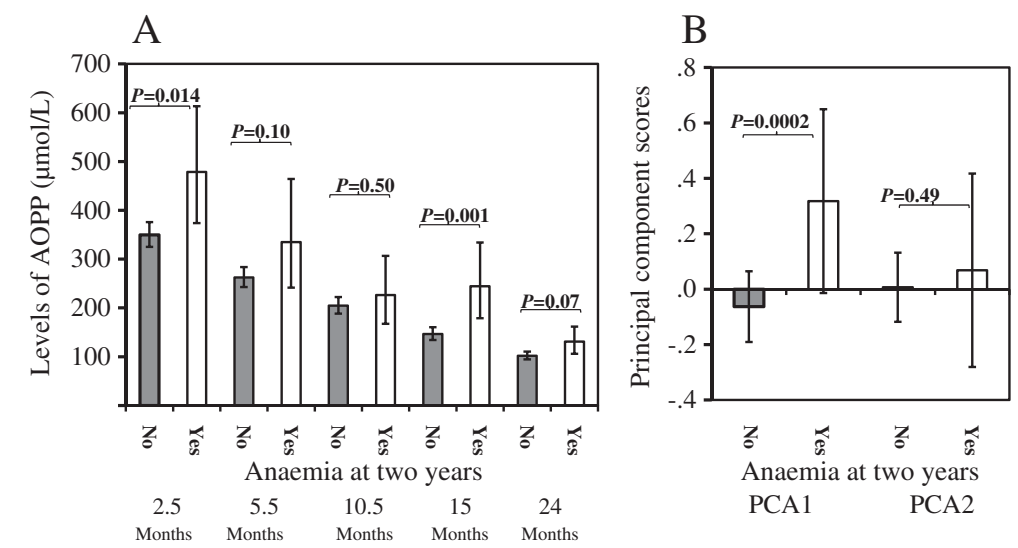

Figure 2 AOPP levels at the five time points and PCA scores (mean and 95\% confidence intervals) stratified by anaemia at two years. A: AOPP levels (geometric mean and 95\% confidence intervals) at the five time points; B: PCA scores (geometric mean and $95 \%$ confidence intervals); Anaemia was defined at age two years. 

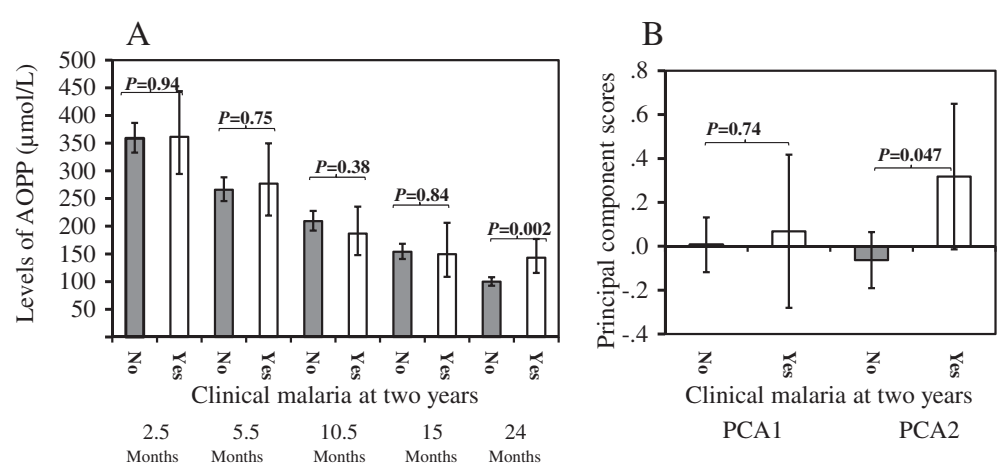

Figure 3 AOPP levels at the five time points and PCA scores stratified by clinical malaria at two years. A: AOPP levels (geometric mean and $95 \%$ confidence intervals) at the five time points; B: PCA scores (mean and 95\% confidence intervals); Clinical malaria was defined at age two years.

percentage of anaemia relative to children with CA or AA genotypes, but this difference was not statistically significant (9.3\% vs. $2.2 \%, \mathrm{p}=0.11)$ (Figure $5 \mathrm{~B})$.

\section{Mixed linear regression model analyses on the} associations of genotypes and AOPP plasma levels

Using a mixed linear regression model, the associations of genotypes were investigated with the AOPP plasma levels measured at the five time points. The model showed that the variables age (the five time points) and anaemia (presence/absence) were significantly associated with the plasma AOPP levels, with the presence of anaemia being associated with higher AOPP levels and age associated with decreased AOPP. After adjusting for age and presence/absence of anaemia the SNPs GCLC RS10948751 and HMOX1 RS17885925 were also significantly associated with the levels of AOPP ( $\mathrm{p}=0.030$ and $\mathrm{p}=0.027$, respectively). Figure 6 shows the levels of AOPP (adjusted for age and anaemia) for the different genotypes of these two SNPs. In the regression model

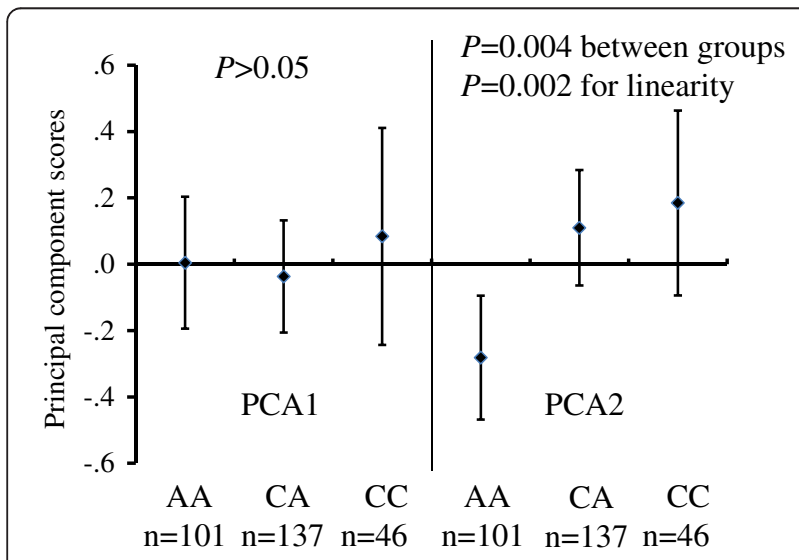

Figure 4 Associations of the GCLC RS10948751 genotype with the PCA scores (mean and 95\% confidence intervals); Analysis of variance was employed for data analysis. analysis, the effects of gender, maternal malaria infection and intervention were not significantly associated to the AOPP levels.

\section{Discussion}

This is the first study to investigate the complex relationships between oxidative stress pathway genes, the oxidative stress biomarker AOPP, anaemia and clinical
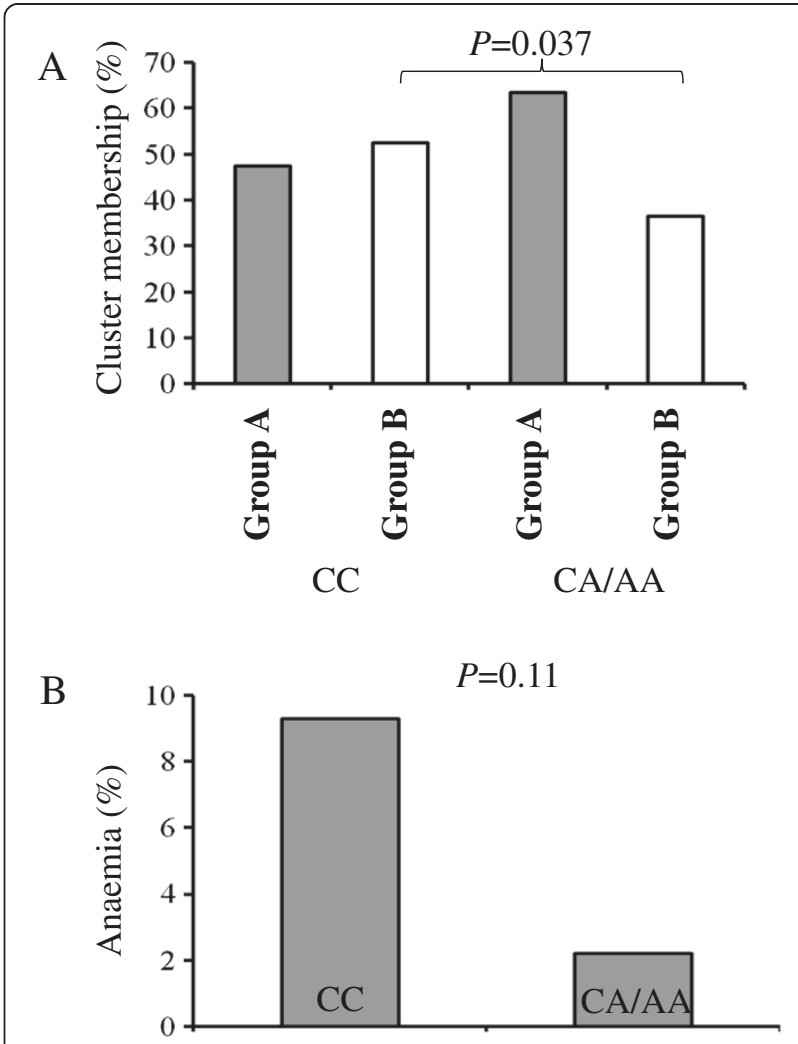

Figure 5 Associations of the GSR RS3594 genotype with the cluster membership and with anaemia; Chi-square tests were used. A: GSR RS3594 and cluster membership; B. GSR RS3594 and anaemia. 

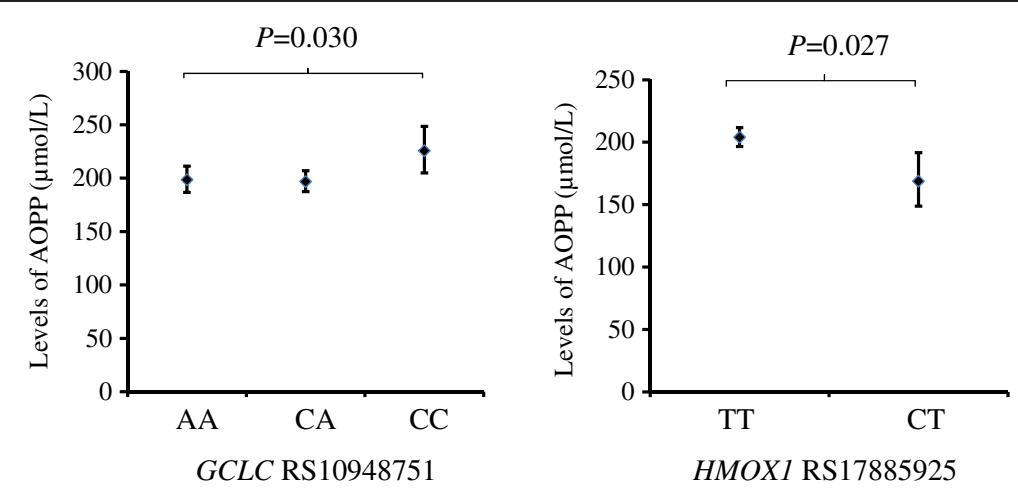

Figure 6 Associations of plasma AOPP levels (geometric mean and 95\% confidence intervals) with the genotypes of GCLC RS10948751 and HMOX1 RS17885925; Mixed linear model was employed and adjusted geometric means (adjusted for age and anaemia) were presented.

malaria infection in a longitudinal cohort of young children. The findings in this study are: (1) Plasma AOPP is a valuable oxidative stress biomarker of anaemia and clinical malaria infection in children two years old living in a malaria endemic area; (2) Preceding levels of AOPP predict to some extent the development of anaemia in children two years old; and (3) Variants in GCLC, GSR and $H M O X 1$ genes are associated with the host oxidative stress status, which was evidenced by their associations with AOPP levels. This study provides valuable data to explain the complex oxidative stress phenomena in children regarding anaemia and clinical malaria infection.

AOPP are biomarkers for oxidative stress, and were first detected in the plasma of chronic uraemic patients [20]. In addition, AOPP have been investigated for associations with many other chronic conditions such as allergic rhinitis [31], severe obesity [32,33], inflammatory bowel disease [34], atherosclerosis [35], coronary artery disease [36], ulcerative colitis [37], and many others [38-42]. There is evidence that AOPP are both biomarkers of an imbalance between pro-oxidants and antioxidants, and mediators of inflammation [22,41,43]. In this study conducted on a longitudinal cohort of children enrolled at birth, it has clearly been demonstrated that children with anaemia at age two years had increased plasma AOPP levels at ages 2.5, 5.5, 10.5, 15 and 24 months. Moreover, based on the levels of AOPP, children were stratified into two groups using K-Means Cluster techniques, and children in Group B (higher AOPP levels) had more than four times increased risk for anaemia at age two years relative to children in Group A (lower AOPP levels). The association observed between AOPP levels measured just after birth and the presence of anaemia at age two years suggests that the early oxidative stress burden predicts the later development of anaemia in young children living in a malaria endemic area. Children with clinical malaria infection at age two years had concurrently higher levels of AOPP, which may have resulted from the simultaneous interdependence of oxidative stress with malaria infection. In addition, clinical malaria infection at age two years was associated with a higher score for PCA2 that was positively correlated with AOPP levels at age 24 months, and negatively correlated with AOPP levels at ages 2.5 and 5.5 months. Since PCA2 only explained $20 \%$ of the variation of AOPP levels at the five time points, there was insufficient evidence that the early levels of AOPP at 2.5 and 5.5 months, possibly related to early malaria exposure, were associated with a protective effect against later clinical malaria. Moreover, the raw analysis on the association between AOPP levels at 2.5 and 5.5 months did not support this relationship. Interestingly however, the RBC oxidative stress marker 4-hydroxynonenalconjugates, was recently reported to be associated with malaria susceptibility in young children [27]. Therefore, more studies, using AOPP as biomarkers are indicated to further elucidate the relationship between early oxidative burden, and later susceptibility to clinical malaria. However, the data in the present study showed that AOPP levels were an early predictor for anaemia and a simultaneous oxidative stress biomarker of clinical malaria in two years old children.

The main goal of this study was to investigate the associations of 12 functionally important polymorphisms in five oxidative stress pathway genes with plasma AOPP levels. One polymorphism which violated the HardyWeinberg equilibrium and one redundant polymorphism were excluded, thus only 10 were included in the analyses. To circumvent multiple tests, the relationships were examined of these 10 polymorphisms with the two PCA scores derived from the AOPP levels at the five time points. The GCLC SNP RS10948751 was associated with PCA2, and the further mixed linear regression model analysis confirmed the association of this SNP 
with plasma AOPP levels. There are no reports investigating associations of variations of the GCLC gene with susceptibility to malaria or with the biomarker AOPP. However, a few studies have reported that the SNP -129 $\mathrm{C} / \mathrm{T}$ and the TNR (GAG trinucleotide repeat) polymorphism in the GCLC gene are associated with several clinical phenotypes such as type 1 diabetes [44], chronic beryllium disease [45], depression [46] and lung function and growth [47]. This study provides new evidence that sequence variations of the glutamate cysteine ligase gene are related to the anti-oxidative stress-response. Consistent with a previous study [45] the polymorphismassociated variation in the AOPP levels may increase pro-inflammatory phagocyte activity thus inducing lipidperoxidation activity with subsequent oxidative plasma and RBC membrane modifications [48], decreased RBC filterability [3], enhanced RBC phagocytosis [49] and defective erythropoiesis [48]. These cellular processes may partly explain the associations found between polymorphisms in this gene and anaemia. In addition, one variant in the GSR gene (RS3594) was associated with cluster membership based on AOPP levels measured longitudinally during the first two years of life. Polymorphisms in the GSR gene have been associated with postmenopausal bone mineral density values [17] and COPD [11]. This study provides evidence for the functional importance of polymorphisms in the GSR gene in relation to oxidative stress in an inflammatory disease. In case of an association between the GSR polymorphisms and a low anti-oxidant glutathione reducing activity, increased AOPP values would be the direct consequence of any inflammatory response or oxidation by the malaria parasite growing in RBCs. Indeed, P-falciparum-parasitized RBCs with these GSR phenotypes were reported to show increased in-vitro phagocytosis rates due to membrane oxidations [50]. Similar mechanisms might play a role in vivo and explain the association of the GSR polymorphism with anaemia. A few studies have investigated the associations of the HMOX1 gene polymorphisms with malaria susceptibility in humans $[16,19,51]$. A microsatellite polymorphism (GT)n was found to be associated with HMOX1 expression and development of symptomatic or severe malaria $[16,19]$. The present study found that the HMOX1 RS17885925 polymorphism was associated with AOPP levels. However, considering the linkage disequilibrium between polymorphisms in this gene, the effect of HMOX1 RS17885925 on the AOPP levels may be attributed to other intragenic variants $[16,19]$.

The main limitation of this study was that the longitudinal cohort had a small sample size (less than 300 children at age two years). As the subjects were recruited from a general African community, the prevalence of anaemia and clinical malaria infection was less than $12 \%$, with only 23 anaemic children and 32 children with clinical malaria infection at age two years. This study, therefore, did not have sufficient statistical power to investigate the associations of the different genotypes with the anaemia and clinical malaria infection phenotypes. However, AOPP plasma levels were longitudinally measured, and this has provided a comprehensive assessment of the children's oxidative status and allowed a systematic examination of the complex interrelationships between AOPP plasma levels, polymorphisms in several oxidative stress pathway genes and anaemia and clinical malaria infection in the longitudinal cohort.

In conclusion, the present study has identified several polymorphisms in GCLC, GSR and HMOX1 genes that are associated with oxidative stress status in the blood plasma of two-year old children from a malaria endemic region. In addition, plasma AOPP is an oxidative stress marker for clinical malaria in these children and that AOPP levels are predictive for anaemia.

\section{Additional file}

Additional file 1: Table S1. Polymorphisms in the five oxidative pathway genes. Table S2. Component matrix of levels of AOPP at five times with two principal component scores.

\section{Competing interest}

The authors do not have any commercial or other association that might pose a conflict of interest. The funding sources did not have any involvement in study design, collection, analysis and interpretation of data, writing of the report, or in the decision to submit the paper for publication. The researchers are independent from the funders.

\section{Authors' contributions}

$G Z, E S, P N L, C D, P L A, J G$ contributed to conception and design of the study; TM, RA, OAS, ES, KSK, SW, CMH, AN, MNM, AB, CG contributed to acquisition of data; SW, KSK, CMH contributed to selection of genes and polymorphisms; GZ, MSM, LQ analyzed the data; all authors contributed to interpretation of data; GZ drafted the article; all authors revised the article critically for important intellectual content; all authors read and gave final approval of the version to be published.

\section{Acknowledgments}

We are very grateful to all volunteers and their families for participating in the study; the staff of the Manhiça District Hospital and CISM, clinicians, field supervisors and data entry clerks; Mauricio H. Rodríguez, Lázaro Mussacate Quimice and Nelito Ernesto José for sample processing. Thanks are due to Paolo Arese for helpful discussion of the data. The study received financial support from the EU FP6 (LSHP-CT-2005-18902), the Spanish Ministerio de Ciencia e Innovación (SAF2005-25642-E, salary support RYC-2008-02631 to C. D.), the Instituto de Salud Carlos III (A107190024, salary support CM04/00028 to C.G.), the BioMalPar program (European Grant number LSHP-CT-2004503578) and EVIMalaR (Grant No : 242095) and the Italian Ministry of Education, University and Research (salary support to O.A.S.), the National Health and Medical Research Council (NHMRC), and the Bright Spark Foundation (salary support to G.Z.). The Centro de Investigação em Saúde de Manhiça receives core support from the Spanish Agency for International Cooperation and Development (AECID).

\section{Author details}

${ }^{1}$ School of Paediatrics and Child Health, University of Western Australia, c/o 100 Roberts Rd, Subiaco, WA 6008 Perth, Australia. ²Department of Oncology, University of Torino, Torino, Italy. ${ }^{3}$ Centro de Investigação em Saúde de Manhiça (CISM), Maputo, Mozambique. ${ }^{4}$ Barcelona Centre for International Health Research (CRESIB, Hospital Clínic, Universitat de Barcelona), Barcelona, 
Spain. ${ }^{5}$ CIBER Epidemiología y Salud Pública (CIBERESP), Barcelona, Spain. ${ }^{6}$ School of Public Health, Curtin University, Perth, Australia.

Received: 2 December 2013 Accepted: 27 March 2014 Published: 3 April 2014

\section{References}

1. Bozdech Z, Ginsburg H: Antioxidant defense in plasmodium falciparum-data mining of the transcriptome. Malar J 2004, 3:23.

2. Baskurt OK, Temiz A, Meiselman HJ: Effect of superoxide anions on red blood cell rheologic properties. Free Radic Biol Med 1998, 24:102-110.

3. Skorokhod A, Schwarzer E, Gremo G, Arese P: HNE produced by the malaria parasite Plasmodium falciparum generates HNE-protein adducts and decreases erythrocyte deformability. Redox Rep 2007, 12:73-75.

4. Becker K, Tilley L, Vennerstrom JL, Roberts D, Rogerson S, Ginsburg H: Oxidative stress in malaria parasite-infected erythrocytes: host-parasite interactions. Int J Parasitol 2004, 34:163-189.

5. Murdzoska J, Devadason SG, Khoo SK, Landau LI, Young S, Goldblatt J, Zhang G, Le Souef PN, Hayden CM: In utero smoke exposure and role of maternal and infant glutathione s-transferase genes on airway responsiveness and lung function in infancy. Am I Respir Crit Care Med 2010, 181:64-71.

6. Schultz EN, Devadason SG, Khoo SK, Zhang G, Bizzintino JA, Martin AC, Goldblatt J, Laing IA, Le Souef PN, Hayden CM: The role of GSTP1 polymorphisms and tobacco smoke exposure in children with acute asthma. J Asthma 2010, 47:1049-1056.

7. Kavishe RA, Bousema T, Shekalaghe SA, Sauerwein RW, Mosha FW, van der Ven AJ, Russel FG, Koenderink JB: Common genotypic polymorphisms in glutathione S-transferases in mild and severe falciparum malaria in Tanzanian children. Am J Trop Med Hyg 2009, 81:363-365.

8. Kavishe RA, Koenderink JB, McCall MB, Peters WH, Mulder B, Hermsen CC, Sauerwein RW, Russel FG, Van der Ven AJ: Severe Plasmodium falciparum malaria in Cameroon: associated with the glutathione S-transferase M1 null genotype. Am J Trop Med Hyg 2006, 75:827-829.

9. Poonkuzhali B, Shaji RV, Salamun DE, George B, Srivastava A, Chandy M: Cytochrome P4501A1 and glutathione S transferase gene polymorphisms in patients with aplastic anemia in India. Acta Haematol 2005, 114:127-132.

10. Minelli C, Granell R, Newson R, Rose-Zerilli MJ, Torrent M, Ring SM, Holloway JW, Shaheen SO, Henderson JA: Glutathione-S-transferase genes and asthma phenotypes: a human genome epidemiology (HuGE) systematic review and meta-analysis including unpublished data. Int I Epidemiol 2010, 39:539-562.

11. Bentley AR, Emrani P, Cassano PA: Genetic variation and gene expression in antioxidant related enzymes and risk of COPD: a systematic review. Thorax 2008, 63:956-961.

12. Ordovas JM: Genetic links between diabetes mellitus and coronary atherosclerosis. Curr Atheroscler Rep 2007, 9:204-210.

13. Di Pietro G, Magno LA, Rios-Santos F: Glutathione S-transferases: an overview in cancer research. Expert Opin Drug Metab Toxicol 2010, 6:153-170.

14. Nichenametla SN, Lazarus P, Richie JP Jr: A GAG trinucleotide-repeat polymorphism in the gene for glutathione biosynthetic enzyme, GCLC, affects gene expression through translation. FASEB J 2011, 25:2180-2187.

15. Oliveira CP, Stefano JT, Cavaleiro AM, Zanella Fortes MA, Vieira SM, Rodrigues Lima VM, Santos TE, Santos VN, de Azevedo Salgado AL, Parise ER, Ferreira Alves VA, Carrilho FJ, Correa-Giannella ML: Association of polymorphisms of glutamate-cystein ligase and microsomal triglyceride transfer protein genes in non-alcoholic fatty liver disease. J Gastroenterol Hepatol 2010, 25:357-361.

16. Mendonca VR, Luz NF, Santos NJ, Borges VM, Goncalves MS, Andrade BB, Barral-Netto M: Association between the haptoglobin and heme oxygenase 1 genetic profiles and soluble CD163 in susceptibility to and severity of human malaria. Infect Immun 2012, 80:1445-1454

17. Mlakar SJ, Osredkar J, Prezelj J, Marc J: Antioxidant enzymes GSR, SOD1, SOD2, and CAT gene variants and bone mineral density values in postmenopausal women: a genetic association analysis. Menopause 2012, 19:368-376.

18. Pamplona A, Ferreira A, Balla J, Jeney V, Balla G, Epiphanio S, Chora A, Rodrigues CD, Gregoire IP, Cunha-Rodrigues M, Portugal S, Soares MP, Mota MM: Heme oxygenase-1 and carbon monoxide suppress the pathogenesis of experimental cerebral malaria. Nat Med 2007, 13:703-710.
19. Walther M, De Caul A, Aka P, Njie M, Amambua-Ngwa A, Walther B, Predazzi IM, Cunnington A, Deininger S, Takem EN, Ebonyi A, Weis S, Walton R, Rowland-Jones S, Sirugo G, Williams SM, Conway DJ: HMOX1 gene promoter alleles and high HO-1 levels are associated with severe malaria in Gambian children. PLoS Pathog 2012, 8:e1002579.

20. Witko-Sarsat V, Friedlander M, Capeillere-Blandin C, Nguyen-Khoa T, Nguyen AT, Zingraff J, Jungers P, Descamps-Latscha B: Advanced oxidation protein products as a novel marker of oxidative stress in uremia. Kidney Int 1996, 49:1304-1313.

21. Selmeci L, Szekely M, Soos P, Seres L, Klinga N, Geiger A, Acsady G: Human blood plasma advanced oxidation protein products (AOPP) correlates with fibrinogen levels. Free Radic Res 2006, 40:952-958.

22. Selmeci L: Advanced oxidation protein products (AOPP): novel uremic toxins, or components of the non-enzymatic antioxidant system of the plasma proteome? Free Radic Res 2011, 45:1115-1123.

23. Witko-Sarsat V, Gausson V, Descamps-Latscha B: Are advanced oxidation protein products potential uremic toxins? Kidney Int Suppl 2003, 63:S11-S14

24. Guinovart C, Dobano C, Bassat Q, Nhabomba A, Quinto L, Manaca MN, Aguilar R, Rodriguez MH, Barbosa A, Aponte JJ, Mayor AG, Renom M, Moraleda C, Roberts DJ, Schwarzer E, Le Souef PN, Schofield L, Chitnis CE, Doolan DL, Alonso PL: The role of age and exposure to Plasmodium falciparum in the rate of acquisition of naturally acquired immunity: a randomized controlled trial. PLoS One 2012, 7:e32362.

25. Alonso PL, Sacarlal J, Aponte JJ, Leach A, Macete E, Milman J, Mandomando I, Spiessens B, Guinovart C, Espasa M, Bassat Q, Aide P, Ofori-Anyinam O, Navia MM, Corachan S, Ceuppens M, Dubois MC, Demoitie MA, Dubovsky F, Menendez C, Tornieporth N, Ballou WR, Thompson R, Cohen J: Efficacy of the RTS, S/AS02A vaccine against plasmodium falciparum infection and disease in young African children: randomised controlled trial. Lancet 2004, 364:1411-1420.

26. Zhang G, Manaca MN, McNamara-Smith M, Mayor A, Nhabomba A, Berthoud TK, Khoo SK, Wiertsema S, Aguilar R, Barbosa A, Quinto L, Candelaria P, Schultz EN, Hayden CM, Goldblatt J, Guinovart C, Alonso PL, Lesouef PN, Dobano C: Interleukin-10 (IL-10) polymorphisms are associated with IL-10 production and clinical malaria in young children. Infect Immun 2012, 80:2316-2322.

27. Aguilar R, Marrocco T, Skorokhod OA, Barbosa A, Nhabomba A, Manaca MN, Guinovart C, Quinto L, Arese P, Alonso PL, Dobano C, Schwarzer E: Blood oxidative stress markers and plasmodium falciparum malaria in non-immune African children. Br J Haematol 2014, 164:438-450.

28. Gabriel S, Ziaugra L, Tabbaa D: SNP genotyping using the sequenom massarray iplex platform. Curr Protoc Hum Genet 2009, Unit 2(Chapter 2):12. http://www.ncbi.nlm.nih.gov/pubmed/19170031.

29. Witko-Sarsat V, Friedlander M, Nguyen Khoa T, Capeillere-Blandin C, Nguyen AT, Canteloup S, Dayer JM, Jungers P, Drueke T, Descamps-Latscha B: Advanced oxidation protein products as novel mediators of inflammation and monocyte activation in chronic renal failure. J Immunol 1998, 161:2524-2532.

30. Innate immunity in heart, lung and blood disease programs for genomic applications. https://regepi.bwh.harvard.edu/IPGA2/.

31. Aksoy F, Yildirim YS, Veyseller B, Demirhan H, Ozturan O: Serum levels of advanced oxidation protein products in response to allergen exposure in allergic rhinitis. Ear Nose Throat J 2012, 91:E32-E35.

32. Codoner-Franch P, Tavarez-Alonso S, Murria-Estal R, Tortajada-Girbes M, Simo-Jorda R, Alonso-Iglesias E: Elevated advanced oxidation protein products (AOPPs) indicate metabolic risk in severely obese children. Nutr Metab Cardiovasc Dis 2012, 22:237-243.

33. Krzystek-Korpacka M, Patryn E, Boehm D, Berdowska I, Zielinski B, Noczynska A: Advanced oxidation protein products (AOPPs) in juvenile overweight and obesity prior to and following weight reduction. Clin Biochem 2008, 41:943-949.

34. Krzystek-Korpacka M, Neubauer K, Berdowska I, Boehm D, Zielinski B, Petryszyn P, Terlecki G, Paradowski L, Gamian A: Enhanced formation of advanced oxidation protein products in IBD. Inflamm Bowel Dis 2008, 14:794-802.

35. Liu SX, Hou FF, Guo ZJ, Nagai R, Zhang WR, Liu ZQ, Zhou ZM, Zhou M, Xie $D$, Wang GB, Zhang $X$ : Advanced oxidation protein products accelerate atherosclerosis through promoting oxidative stress and inflammation. Arterioscler Thromb Vasc Biol 2006, 26:1156-1162.

36. Kaneda H, Taguchi J, Ogasawara K, Aizawa T, Ohno M: Increased level of advanced oxidation protein products in patients with coronary artery disease. Atherosclerosis 2002, 162:221-225. 
37. Alagozlu H, Gorgul A, Bilgihan A, Tuncer C, Unal S: Increased plasma levels of advanced oxidation protein products (AOPP) as a marker for oxidative stress in patients with active ulcerative colitis. Clin Res Hepatol Gastroenterol 2012, 37:80-85.

38. Iwao Y, Nakajou K, Nagai R, Kitamura K, Anraku M, Maruyama T, Otagiri M: CD36 is one of important receptors promoting renal tubular injury by advanced oxidation protein products. Am J Physiol Renal Physiol 2008, 295:F1871-F1880.

39. Anraku M, Kitamura K, Shintomo R, Takeuchi K, Ikeda H, Nagano J, Ko T, Mera K, Tomita K, Otagiri M: Effect of intravenous iron administration frequency on AOPP and inflammatory biomarkers in chronic hemodialysis patients: a pilot study. Clin Biochem 2008, 41:1 168-1174.

40. Liu H, Han T, Tian J, Zhu ZY, Liu Y, Li Y, Xiao SX, Feng YY: Monitoring oxidative stress in acute-on-chronic liver failure by advanced oxidation protein products. Hepatol Res 2012, 42:171-180.

41. Wykretowicz A, Adamska K, Krauze T, Guzik P, Szczepanik A, Rutkowska A, Wysoki H: The plasma concentration of advanced oxidation protein products and arterial stiffness in apparently healthy adults. Free Radic Res 2007, 41:645-649.

42. Baskol G, Gumus K, Oner A, Arda H, Karakucuk S: The role of advanced oxidation protein products and total thiols in diabetic retinopathy. Eur J Ophthalmol 2008, 18:792-798.

43. Witko-Sarsat $V$, Nguyen Khoa T, Jungers P, Drueke T, Descamps-Latscha B: Advanced oxidation protein products: oxidative stress markers and mediators of inflammation in uremia. Adv Nephrol Necker Hosp 1998, 28:321-341.

44. Bekris LM, Shephard C, Janer M, Graham J, McNeney B, Shin J, Zarghami M, Griffith W, Farin F, Kavanagh TJ, Lernmark A: Glutamate cysteine ligase catalytic subunit promoter polymorphisms and associations with type 1 diabetes age-at-onset and GAD65 autoantibody levels. Exp Clin Endocrinol Diabetes 2007, 115:221-228.

45. Bekris LM, Viernes HM, Farin FM, Maier LA, Kavanagh TJ, Takaro TK: Chronic beryllium disease and glutathione biosynthesis genes. J Occup Environ Med 2006, 48:599-606.

46. Berk M, Johansson S, Wray NR, Williams L, Olsson C, Haavik J, Bjerkeset O: Glutamate cysteine ligase (GCL) and self reported depression: an association study from the HUNT. J Affect Disord 2011, 131:207-213.

47. Breton CV, Salam MT, Vora H, Gauderman WJ, Gilliland FD: Genetic variation in the glutathione synthesis pathway, air pollution, and children's lung function growth. Am J Respir Crit Care Med 2011, 183:243-248.

48. Skorokhod OA, Caione L, Marrocco T, Migliardi G, Barrera V, Arese P, Piacibello W, Schwarzer E: Inhibition of erythropoiesis in malaria anemia: role of hemozoin and hemozoin-generated 4-hydroxynonenal. Blood 2010, 116:4328-4337.

49. Uyoga S, Skorokhod OA, Opiyo M, Orori EN, Williams TN, Arese P, Schwarzer E: Transfer of 4-hydroxynonenal from parasitized to non-parasitized erythrocytes in rosettes. Proposed role in severe malaria anemia. Br J Haematol 2012, 157:116-124.

50. Gallo V, Schwarzer E, Rahlfs S, Schirmer RH, van Zwieten R, Roos D, Arese P, Becker K: Inherited glutathione reductase deficiency and Plasmodium falciparum malaria-a case study. PLoS One 2009, 4:e7303.

51. Sambo MR, Trovoada MJ, Benchimol C, Quinhentos V, Goncalves L, Velosa R, Marques MI, Sepulveda N, Clark TG, Mustafa S, Wagner O, Coutinho A, Penha-Goncalves C: Transforming growth factor beta 2 and heme oxygenase 1 genes are risk factors for the cerebral malaria syndrome in Angolan children. PLoS One 2010, 5:e11141.

doi:10.1186/1475-2875-13-134

Cite this article as: Zhang et al:: Plasma advanced oxidative protein products are associated with anti-oxidative stress pathway genes and malaria in a longitudinal cohort. Malaria Journal 2014 13:134.

\section{Submit your next manuscript to BioMed Central and take full advantage of:}

- Convenient online submission

- Thorough peer review

- No space constraints or color figure charges

- Immediate publication on acceptance

- Inclusion in PubMed, CAS, Scopus and Google Scholar

- Research which is freely available for redistribution

Submit your manuscript at www.biomedcentral.com/submit 